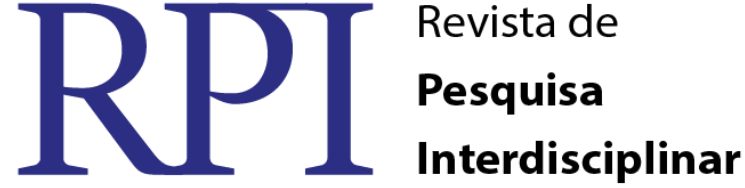

\section{"DESCOBRINDO OS ELEMENTOS QUÍMICOS": JOGO LÚDICO PROPORCIONANDO UMA APRENDIZAGEM SIGNIFICATIVA SOBRE A TABELA PERÍODICA}

\author{
Egle Katarinne Souza da Silva - UFCG/CFP/UACEN \\ João Paulo Ferreira Lima - UFCG/CFP/UACEN \\ Maricélia Lucena Ferreira - UFCG/CFP/UACEN
}

\begin{abstract}
RESUMO
Com a participação de 33 discentes do primeiro período do curso de licenciatura em Química da Universidade Federal de Campina Grande, localizada no município de Cajazeiras do Estado da Paraíba, desenvolveu-se a presente pesquisa na perspectiva de identificar as percepções, bem como o embasamento teórico que estes estudantes trazem do ensino médio em relação à Tabela Periódica dos Elementos Químicos. Com a finalidade de verificar o conhecimento de cada aluno referente à proposta de estudo aplicada neste trabalho, inicialmente aplicou-se uma entrevista semiestruturada e posteriormente, como forma dinâmica e com o objetivo de construir uma aprendizagem significativa sobre a temática abordada, aplicou-se o jogo lúdico intitulado: Descobrindo os Elementos Químicos. Após o término do jogo, os alunos envolvidos foram questionados sobre a relevância do lúdico no ensino de química. Trata-se de uma pesquisa aplicada, bibliográfica, quantitativa e qualitativa. Após aferir os resultados percebeu-se que a maioria dos discentes teve dificuldade ou não souberam responder ao questionário que antecedeu a atividade lúdica, apresentando imprecisões sobre conceitos simples que deveriam ser trabalhados de forma efetiva durante o ensino médio, visto que a Tabela Periódica dos Elementos Químicos é a principal base no ensino de Química. Em contra partida, todos os alunos os quais participaram do jogo, afirmaram que não sabiam de todos os conceitos abordados na atividade, bem como reconheceram a importância do lúdico no processo de ensino e aprendizagem da disciplina Química. Diante dos resultados alcançados, pode-se assim constatar a eficácia do jogo aplicado e a relevância de introduzir o lúdico no ensino superior de Química já no início do curso, visando despertar nos ingressantes uma motivação a construírem o próprio conhecimento de forma prazerosa.
\end{abstract}

Palavras chave: Aprendizagem Significativa, Tabela Periódica, Jogo Lúdico.

\section{"DISCOVERING THE CHEMICAL ELEMENTS": LUDIC GAME PROVIDING A MEANINGFUL LEARNING ABOUT THE PERIODIC TABLE}

\begin{abstract}
This research was developed with the participation of 33 students of the first period of the degree in Chemistry Course of the Federal University of Campina Grande, located in the municipality of Cajazeiras in the State of Paraíba, aiming to identify their perceptions and theoretical background that these students bring high school in relation to the Periodic Table of Chemical Elements. In order to verify the knowledge of each student on the proposal of study applied in this work, initially, it was applied semi-structured interview; then it was applied a playful ludic game titled: 'Discovering the Chemical Elements' ('Descobrindo os Elementos Químicos' in original language), in order to build a significant and dynamic learning about the theme. After finishing the game, students involved were asked about the relevance of the play in the teaching of Chemistry. This paper is a bibliographical, quantitative and qualitative research. After assessing the results, it was noticed that the majority of students had difficulty or could not answer the questionnaire that preceded the play activity, presenting inaccuracies on simple concepts that should be worked effectively during high school. Since the Periodic Table of the Chemical Elements is the main base in the teaching of Chemistry. In contrast, all
\end{abstract}


the students who played the game said they were unaware of all the concepts covered in the activity and they recognized the importance of the play in the teaching and learning discipline of Chemistry. On the results achieved, can see the effectiveness of the game applied and the relevance of introducing the ludic in higher education of chemistry in the beginning of the course, aiming at awakening in entering a motivation to build the own knowledge so enjoyable.

Keywords: Meaningful Learning, Periodic Table, Ludic Game.

\section{INTRODUÇÃO}

Nas últimas décadas muito se tem discutido sobre o ensino de química, e os desafios nos quais o mesmo está submetido. Neste contexto, a prática docente precisa deixar os velhos métodos de ensino, onde o professor restringe sua prática docente apenas a transmitir os conteúdos encontrados nos livros e os alunos são apenas meros ouvintes. Sendo um profissional tradicionalista os conteúdos são repassados de forma mecânica, abstrata e sem contextualização impossibilitando a aprendizagem dos alunos.

No processo de ensino aprendizagem o professor precisa ter uma relação interpessoal com seus alunos que possibilite a utilização de metodologias de capazes de envolvê-los e estimulá-los a produzir o próprio conhecimento. Paulo Freire (1993) afirma, que o educador precisa estar à altura de seu tempo. Dessa maneira é necessário que o professor faça uma reflexão crítica sobre sua prática docente e ao mesmo tempo articule métodos que venham romper estereótipo que estudar química é algo difícil, monótono, e repetitivo.

$\mathrm{Na}$ busca por novas metodologias no ensino de química que facilite a compreensão dos conteúdos por parte dos alunos não só no ensino médio como também no ensino superior, os jogos lúdicos se apresentam como uma alternativa inovadora capaz de tornar agradável e compreensível os conceitos químicos. De acordo com Kishimoto (2002). O jogo educativo possui duas funções à função lúdica, que está ligada a diversão, ao prazer e até o desprazer e a função educativa, que objetiva a ampliação dos conhecimentos.

Desenvolveu-se esta pesquisa com 33 alunos do primeiro período do curso de licenciatura em Química da Universidade Federal de Campina Grande (UFCG) campus de Cajazeiras-PB, com o objetivo de identificar com que embasamento teórico sobre a Tabela Periódica estes discentes ingressaram ao ensino superior, bem como proporcionar aos mesmos um ensino dinâmico através da aplicação de um jogo lúdico que aborda conceitos importantes sobre a Tabela Periódica, construindo em conjunto uma aprendizado eficiente, prazeroso e menos monótono.

RPI Revista de Pesquisa Interdisciplinar, Cajazeiras, v. 1, Ed. Especial, 228 - 237, set/dez. de 2016. 


\section{Referencial Teórico}

O estudo dos elementos químicos é o principal alicerce no ensino de Química, desde a história da origem destes até a sua composição fundamental. Portanto, não há como estudar Química sem o conhecimento da Tabela Periódica dos Elementos Químicos.

Ao longo da história grandes teóricos passaram a buscar a melhor organização possível dos Elementos Químicos. Como cita Atkins (2012), este fato se deu bem antes do conhecimento da estrutura do átomo, através de relatos experimentais sobre a periodicidade dos elementos.

A elaboração da Tabela Periódica é para a Química uma das ocorrências mais importantes, pois ela dispõe os Elementos Químicos de forma organizada e metódica, a partir das propriedades físicas e químicas dos elementos. Após conhecer em um congresso o Princípio de Avogadro, o cientista alemão Dmitri Ivanovich Mendeleiev, descobriu os elementos detinham propriedades semelhantes quando dispostos em ordem crescente da massa atômica, observando certa periodicidade nas caracterizações dos elementos e após incansáveis tentativas elaborou a primeira Tabela Periódica dos Elementos Químicos no ano de 1869.

Mendeleiev conseguiu prevê elementos ainda não descobertos, deixando em sua tabela espaços correspondentes as propriedades que correspondiam a estes elementos. Mas com algumas contestações de outros estudiosos em relação a organização dos elementos por ordem massa atômica, Henry G. J. Moseley descobriu pelo estudo dos espectros de raios X dos elementos, que estes tinham uma melhor organização se ordenados pelo número atômico, o que complementou as previsões de Mendeleiev quando deixou lacunas na sua organização dos elementos.

A literatura demonstra que o ensino de química ainda está mecanizado e voltado para o tradicional. Santana (2008) retrata que vários estudos e pesquisas mostram o Ensino de Química, em geral, centralizado na simples memorização e repetição de nomes, fórmulas e cálculos, o que torna a matéria tediosa e monótona, fazendo com que os estudantes não entendam o motivo pelo qual devem estudar química.

RPI Revista de Pesquisa Interdisciplinar, Cajazeiras, v. 1, Ed. Especial, 228 - 237, set/dez. de 2016. 
O maior desafio enfrentado pelos professores de Química nos dias atuais é fazer uma ligação entre o conhecimento ensinado e o cotidiano dos alunos. Nesse contexto é necessário que os docentes estejam bem preparados e que sua formação possibilite um censo crítico, para analisar sua prática docente, bem como identificar suas maiores dificuldades, podendo formular possíveis soluções e aplicá-las no ambiente educacional. Conforme descrito nos Parâmetros Curriculares Nacionais para o Ensino Médio - (PCNEM) Brasil (2002) os conteúdos abordados no ensino de química não devem se resumir à mera transmissão de informações, a qual não apresenta qualquer relação com o cotidiano do aluno, seus interesses e suas vivências.

Uma proposta que contribui para dinamização do ensino de Química é a utilização de jogos lúdicos. Estes propiciam aos discentes uma aproximação com os conteúdos químicos, além de colocar o aluno como agente ativo e participativo na construção do conhecimento, pois o lúdico desperta a curiosidade e o conhecimento cientifico. Para Piaget (1964), o uso de atividades lúdicas é válido quando bem aplicado, pois além do lazer, o lúdico é um método de desenvolvimento intelectual. Ainda segundo Vygotsky (1998), o jogo coloca o educando em situações de repetição de valores e imitação de regras sociais.

Dessa forma os jogos lúdicos induzem o aluno ao raciocínio e a reflexão de suas ações enquanto jogador, sobretudo em sua tomada de decisão na condição de aluno diante dos conhecimentos que necessita compreender. Além de contribuir para o desenvolvimento de competências e habilidades, aumenta a motivação dos alunos perante as aulas de Química, proporciona interação entre aluno- professor- colega e promove a construção do conhecimento.

\section{Metodologia}

Participaram desta pesquisa 33 discentes do primeiro período curso de Licenciatura em Química da Universidade Federal de Campina Grande (UFCG), localizada em CajazeirasPB. Inicialmente na preocupação de identificar o real conhecimento do público envolvido sobre a Tabela Periódica, aplicou-se uma entrevista semiestrutura a fim de coletar as concepções, bem como analisar com que embasamento teórico sobre a temática trabalhada estes discentes chegaram ao ensino superior.

Posteriormente, como forma dinâmica, aplicou-se com a turma o jogo lúdico que foi criado por duas discentes do curso de licenciatura em Química desta mesma instituição, onde RPI Revista de Pesquisa Interdisciplinar, Cajazeiras, v. 1, Ed. Especial, 228 - 237, set/dez. de 2016. 
para aplicação do mesmo pintou-se uma tabela periódica ampliada no pátio em frente a central do bloco de química.

O jogo "Descobrindo os Elementos Químicos”, consiste em um jogo de cartas, onde cada carta traz 04 dicas sobre determinado elemento químico, como: o número atômico; a massa atômica; e etc. Dividiu-se a turma em 02 grupos, onde diante da tabela pintada no pátio os discentes respondiam ao questionamento das cartas narrado pelo aplicador, deslocando-se até o elemento químico questionado, sendo que cada resposta correta pontuava o grupo e em caso de erro cedia a chance de resposta o grupo seguinte.

Em seguida com o objetivo de averiguar a aceitação dos discentes e a relevância do lúdico como ferramenta metodológica aplicou-se um questionário formulado com 04 perguntas.

Trata-se de uma pesquisa aplicada e bibliográfica, pois coletou-se em artigos e periódicos as definições necessárias sobre a tabela periódica e a utilização do lúdico no ensino de Química. Também é uma pesquisa quantitativa, onde através da entrevista quantificou-se os dados aferidos, bem como qualitativa no sentido de analisar a eficiência ou ineficiência do jogo aplicado.

A pesquisa aplicada possibilita levantar e apresentar informações e ações para alunos e professores que podem aplicadas de forma imediata. Para Prodanov e Freitas (2013, p. 60) "as pesquisas dessa natureza estão voltadas mais para a aplicação imediata de conhecimentos em uma realidade circunstancial, relevando o desenvolvimento de teorias". Nesse contexto, o desenvolvimento desta torna-se fundamental, pois aplicou-se o lúdico como ferramenta de ensino e como forma de proporcionar uma aprendizagem significativa aos discentes envolvidos.

Para Doxsey \& De Riz (2007) a abordagem quantitativa destaca a quantificação dos dados coletados e requer um maior tempo no tratamento dos dados além do pesquisador evitar que valores pessoais afetem os resultados obtidos. Já a pesquisa qualitativa, segundo Bogdan \& Biklen (2003), envolve a obtenção de dados descritivos, adquiridos no contato direto do pesquisador com a situação estudada, ressalta mais o processo do que o produto e se preocupa em retratar a perspectiva dos participantes.

\section{Resultados}

RPI Revista de Pesquisa Interdisciplinar, Cajazeiras, v. 1, Ed. Especial, 228 - 237, set/dez. de 2016. 
Os dados coletados no primeiro questionário para sondagem das concepções dos discentes envolvidos na pesquisa sobre a Tabela Periódica foram quantificados e transformados em gráficos.

Na Figura-1 percebe-se que 57\% dos entrevistados não responderam ou não souberam responder quem idealizou a Tabela Periódica e outros 44\% afirmaram ter sido Mendeleiev. $\mathrm{Na}$ Figura-2 percebe-se que 43,5\% dos discentes afirmaram que a Tabela serve para separar os Elementos Químicos por característica, outros 30,5\% disseram que a função é distribuir os elementos por massa atômica e com o mesmo percentual de $13 \%$ respectivamente realizar consultas e não responderam. Apenas $44 \%$ dos discentes acertaram quando afirmaram que a tabela periódica foi idealizada por Mendeleiev, referente ao segundo questionamento a literatura afirma que a tabela periódica foi idealizada a partir da necessidade de se organizar os elementos químicos, sendo que estes são ordenados pelo número atômico.

Figura-1: Quem idealizou a Tabela Periódica Figura-2: Qual a necessidade da Tabela

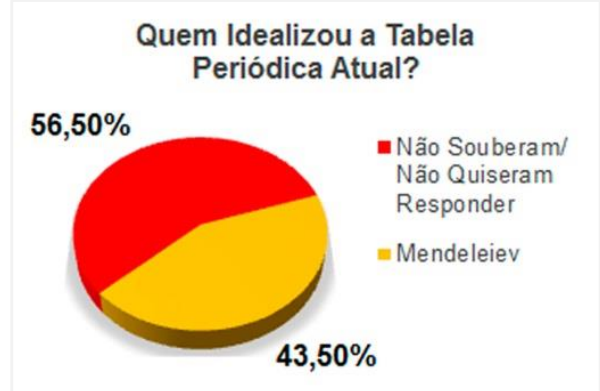

Fonte: Próprio Autor

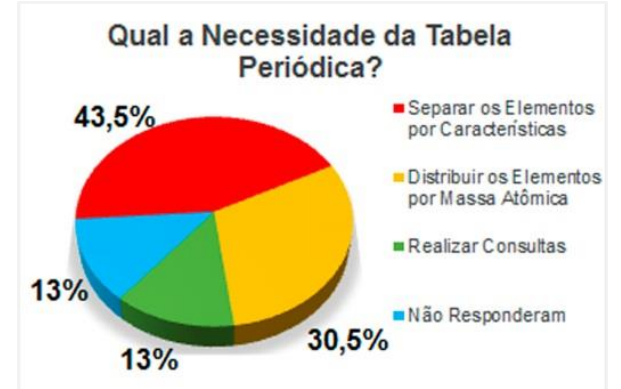

Fonte: Próprio Autor

Na Figura-3 todos os entrevistados afirmaram que os Elementos Químicos não foram descobertos ao mesmo tempo, dado positivo, porém eles não souberam detalhar essa resposta. Na Figura-4 percebe-se que 57\% dos alunos afirmaram que a tabela periódica é universal em contrapartida $43 \%$ não responderam. Embora todos os alunos tenham consciência que a descoberta dos Elementos Químicos ocorreu de forma gradativa, os dados evidenciam que um percentual considerável de $43 \%$ deste não apresentaram resposta quanto a possível hipótese de se existir mais de uma tabela, deixando claro a falta de conhecimento.

RPI Revista de Pesquisa Interdisciplinar, Cajazeiras, v. 1, Ed. Especial, 228 - 237, set/dez. de 2016. 
Figura-3: Descoberta dos Elementos

Todos os Elementos foram

Descobertos ao mesmo tempo?

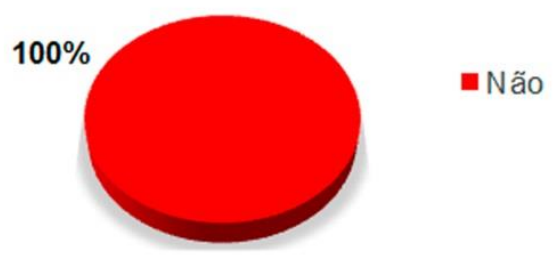

Fonte: Próprio Autor
Figura-4: Cada País tem uma Tabela

Cada Pais tem uma Tabela

Periódica?

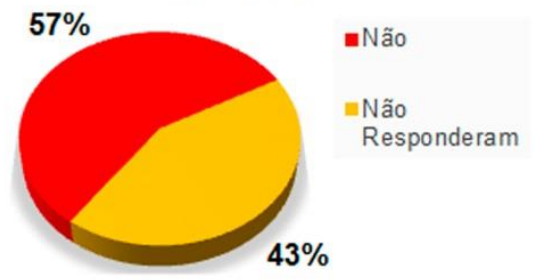

Fonte: Próprio Autor

Na Figura-5 evidencia-se que $44 \%$ dos alunos não responderam ou não souberam responder como são denominadas as linhas horizontais da tabela, outros 35\% denominaram período e $21 \%$ definiram como família/grupo. Na Figura-6 percebe-se que $44 \%$ dos entrevistados também não responderam como são denominadas as linhas verticais da Tabela Periódica, outros $39 \%$ denominaram de família e 17\% afirmaram período. A maioria dos alunos não souberam responder as duas questões, apenas $35 \%$ destes acertaram quando denominaram as linhas horizontais como período e outros $39 \%$ também acertaram em definir as linhas verticais como família, porém este termo vem sendo substituído por grupo.

Figura-5: Linhas Horizontais

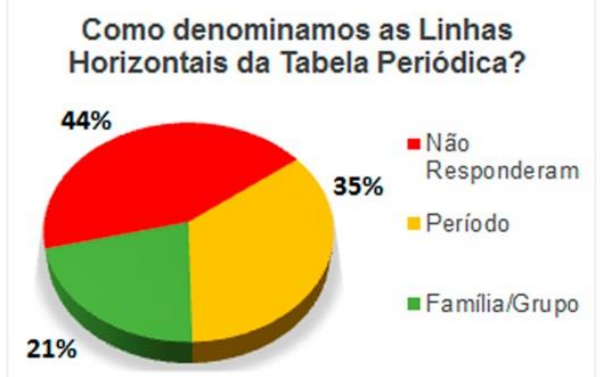

Fonte: Próprio Autor
Figura-6: linhas Verticais

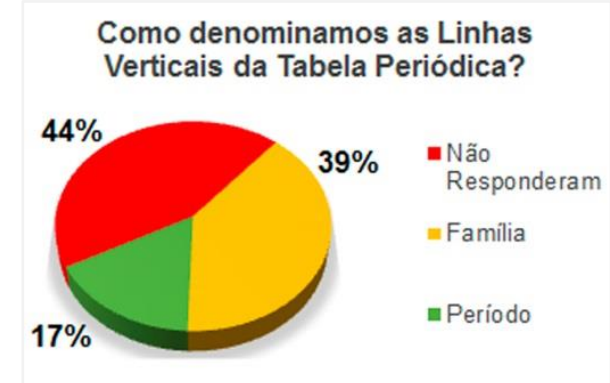

Fonte: Próprio Autor

Na Figura-7 percebe-se que 52\% dos discentes afirmaram que os elementos são classificados como Metais/Não Metais/ Gases Nobres, outros 30\% não responderam e 18\% disseram que os Elementos Químicos são classificados de acordo com sua atomicidade e massa molecular. Na Figura-8 evidencia-se que $48 \%$ dos alunos não responderam ou não souberam citar nenhuma propriedade dos Elementos Químicos, com mesmo percentual 26\% respectivamente citaram Massa Molecular/Número Atômico e Sólido/Líquido/Gasoso. Os elementos químicos estão organizados de forma sistemática levando-se em consideração suas características, percebe-se que a maioria dos entrevistados não foram claros ou não souberam responder.

RPI Revista de Pesquisa Interdisciplinar, Cajazeiras, v. 1, Ed. Especial, 228 - 237, set/dez. de 2016. 
Figura-7: Classificação dos Elementos

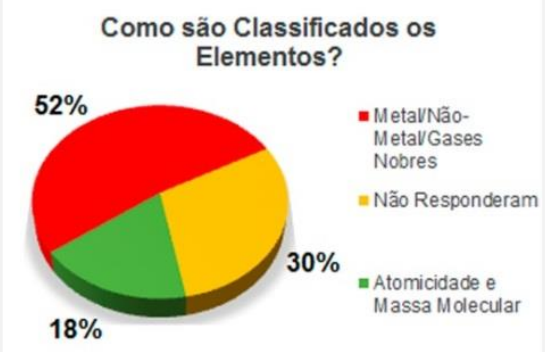

Fonte: Próprio Autor
Figura-8: Propriedades Periódicas

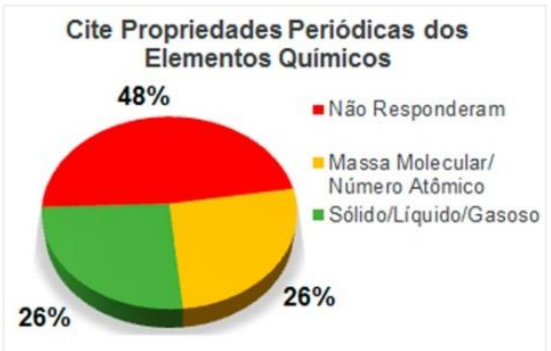

Fonte: Próprio Autor

Diante dos resultados aferidos com o questionário prévio percebeu-se que a grande maioria dos discentes apresentam dificuldade quanto ao estudo da Tabela Periódica, como forma de dinamizar o ensino e facilitar a compreensão dos assuntos relacionados à tabela aplicou-se o jogo lúdico Descobrindo os Elementos Químicos.

Após a aplicação com o objetivo de identificar se os alunos tinham aprovado a atividade lúdica aplicou-se um questionário e transformou-se em gráficos os resultados. Na Figura-09 percebe-se que todos os alunos se identificaram com a experiência vivenciada, sendo que 57\% definiu como uma experiência inovadora, outros $29 \%$ disseram eficiente e 14\% satisfatória. Na Figura-10 a maioria de 95\% dos discentes afirmaram que não tinham conhecimento sobre os assuntos abordados na atividade lúdica, e que conseguiram assimilar todos os conteúdos referentes a Tabela Periódica abordados na atividade.

Figura-09: Definição da Experiência

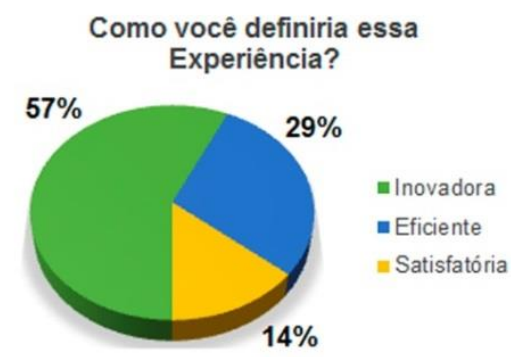

Fonte: Próprio Autor
Figura-10: Já conhecia os conceitos

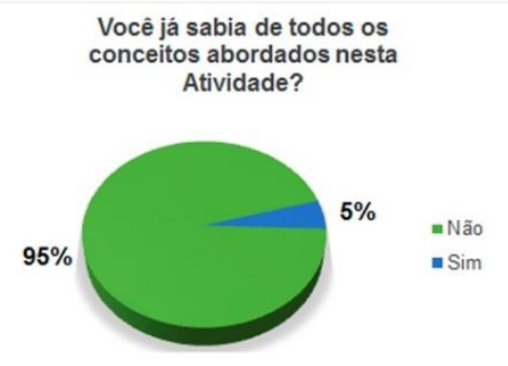

Fonte: Próprio Autor

Na Figura-11 todos os discentes afirmaram a possibilidade de utilizarem o lúdico em sala de aula como forma de atrair os alunos para o mundo da química, bem como aproximar os mesmo do conhecimento cientifico. Na Figura- 12 todos os entrevistados confirmaram que os jogos lúdicos favorecem para compreensão dos conceitos químicos, isto demonstra a aceitabilidade da atividade.

RPI Revista de Pesquisa Interdisciplinar, Cajazeiras, v. 1, Ed. Especial, 228 - 237, set/dez. de 2016. 
Figura-13: Se utilizaria o Lúdico

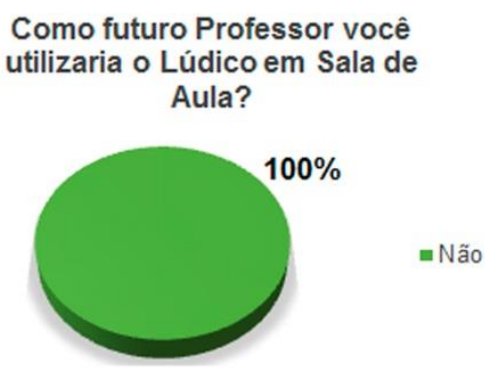

Fonte: Próprio Autor
Figura-14: O Lúdico favorece

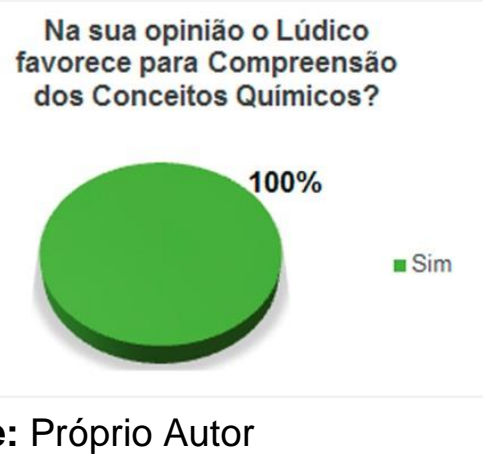

Fonte: Próprio Autor

\section{Conclusão}

Diante do exposto fica evidente a importância do lúdico como ferramenta metodológica no ensino de química. Os resultados demonstram que a maioria dos discentes envolvidos na pesquisa não sabiam de conceitos básicos sobre a Tabela Periódica, demonstrando que adentraram ao superior com dificuldades para interpretar a tabela.

A aplicação do jogo Descobrindo os Elementos Químicos foi eficiente e proporcionou aos discentes uma aprendizagem significativa. Isso fica claro quando todos os alunos classificaram essa experiência como inovadora, eficiente e satisfatória. Dessa forma concluise que lúdico auxiliou de forma prática e agradável na compreensão dos conteúdos necessários para utilização da Tabela Periódica.

\section{REFERÊNCIAS}

ATIKINS, P. W.; JONES, L. Princípios de Química. 5.ed. Porto Alegre: Bookman, 2012.

\section{BRASIL, MEC. As Novas Diretrizes Curriculares que Mudam o Ensino Médio}

Brasileiro, Brasília, 2002.

BOGDAN, R. S.; BIKEN, S. Investigação qualitativa em educação: uma INTRODUÇÃO à teoria e aos métodos. 12.ed. Porto: Porto, 2003.

DOXSEY J. R.; DE RIZ, J. Metodologia da pesquisa científica. ESAB - Escola Superior Aberta do Brasil, 2002-2003. Apostila.

FREIRE, Paulo. Pedagogia do oprimido 30 anos depois. In: FREIRE. A. A.F. Pedagogia dos Sonhos Possíveis. São Paulo: Unesp, 2001.

KISHIMOTO, T.M. O Brincar e suas teorias. São Paulo: Pioneira Thomson Learning, 2002. 
PIAGET, J. A formação do símbolo na criança: imitação, jogo e sonho. Imagem e representação. 3. ed. Rio de Janeiro: Livros técnicos e científicos, 1964, p.114-228.

PRODANOV, C.C.; FREITAS, E. C. de. Metodologia do trabalho científico: métodos e técnicas da pesquisa e do trabalho acadêmico. 2 ed. Novo Hamburgo: Freevale, 2013.

VYGOTSKY, L. S. A Formação social da mente: o desenvolvimento dos processos psicológicos superiores. 6 ed. São Paulo: Martins Fontes, 1998.

SANTANA, E.M.; REZENDE, D.B. O Uso de Jogos no ensino e aprendizagem de Química: Uma visão dos alunos do $9^{\circ}$ ano do ensino fundamental. (2008) Anais do XIV Encontro Nacional de Ensino de Química. Curitiba, Brasil. Disponível em:

$<$ http://www.cienciamao.usp.br/dados/eneq

/_ousodejogosnoensinoeapre.trabalho.pdf>. Acesso em: 12 ago. 2016. 